\title{
ADAPTASI TIGA VARIETAS PEPAYA (MERAH DELIMA, JUPE, MADU) DI LAHAN KERING DATARAN RENDAH
}

\author{
M. Anang Firmansyah ${ }^{\mathbf{1}}$ dan Teguh Pribadi ${ }^{2}$ \\ 1. Balai Pengkajian Teknologi Pertanian Kalimantan Tengah \\ Jl. G. Obos km 5 Palangka Raya 73111 \\ 2. Program Studi Agroteknologi, Fakultas Pertanian, Universitas Muhammadiyah Purwokerto \\ Email: anang.firmansyah75@yahoo.com
}

\begin{abstract}
Papaya fruit (Carica papaya L.) is classified as having high economic value and is being developed by many farmer. A common problem is the papaya variety that farmer $\backslash$ s develop usually from careless seeds, so the production and quality are low. The aim of this research is to introduce superior papaya and have good quality. Three varieties papaya are used in this study, namely: Merah Delima, Jupe, and Madu.The research location is located in the dry land of Banturung, Palangka Raya City. The result that the land suitability class of the study site included S3wa,on, which is Marginal Suitability with the heaviest inhibiting factors of water availability and oxygen availability. On Growth parameters, then Merah Delima has the largest stem circumference of $10,1 \mathrm{~cm}$ althought it is not significantly different from other varieties $8,8 \mathrm{~cm}$. While the plant height is the best Merah Delima papaya and signficantly different from Madu. Interms of Productioan Jupe has a number of Fruits (38 fruits/tree) that are significantly different from Madu, and the weight of fruit (1,2 kg/fruit) is significantly different from Merah Delima., and fruit weight per tree $34,1 \mathrm{~kg}$ is significantly different from the other two varieties. Base on the sweetness level, the sweetest Merah Delima reaches $9,1^{\circ}$ Brix significantly different from Jupe $\left(6,9^{\circ}\right.$ Brix) and Madu $\left(6,6^{\circ}\right.$ Brix). Parameters of growth, productionand quality of papaya can still be improved by improving the management of inhibiting factors.
\end{abstract}

Keywords: Carica papaya L., dry land, level of sweetness

\section{PENDAHULUAN}

Buah pepaya merupakan salah satu jenis buah yang dikenal dan digemari oleh masyarakat luas. Buah ini berasal dari Meksiko bagian selatan hingga Amerika Tengah (Vavilov, 1926 dalam Pesqueira and Farfan, 2017). Manfaat buah pepaya cukup banyak, antara lain memperlancar pencernakan, mencegah katarak, menurunkan radang, mendukung fungsi jantung, hingga meningkatkan daya tahan tubuh (Ali et al. 2011).
Produksi dan mutu buah pepaya dipengaruhi oleh kondisi fotosintesis, cahaya optimum yang dapat diserap akan mendukung kemampuan fotosintesis optimal. Brasilia telah mengembangkan pepaya di rumah kaca yang mampu mengontrol cahaya agar fotosistesis daun pepaya optimal dan hasilnya lebih baik dibandingkan pepaya yang tumbuh di lapangan (Silva et al., 2019).

Di Indonesia, tanaman pepaya umumnya tumbuh menyebar dari dataran rendah sampai dataran tinggi, yaitu sampai $1.000 \mathrm{~m}$ diatas 
permukaan laut. Secara umum tanaman pepaya dapat tumbuh di berbagai jenis tanah. Namun, tanah yang banyak mengandung bahan organik, berdrainase dan aerasi baik, dan memiliki nilai $\mathrm{pH}$ 6,5-7 merupakan kondisi tanah yang sesuai untuk tanaman pepaya (Indriyati et al., 2008).

Tanaman pepaya memiliki kemampuan adaptasi cukup baik dari berbagai jenis tanah. Beberapa jenis tanah seperti tanah mineral lahan kering maupun pasang surut yang memiliki jenis tanah gambut dan tanah sulfat masam juga mampu mendukung tanaman pepaya tumbuh dan berproduksi baik (Martias et al., 2011; Sunyoto et al., 2013; Firmansyah, 2014).

Budidaya pepaya dari aspek ekonomi juga sangat layak untuk dikembangkan. Berdasarkan $\mathrm{B} / \mathrm{C}$ ratio maka kisaran yang diperoleh antara 1,57 hingga 5,50. Artinya nilai dari $\mathrm{B} / \mathrm{C}$ ratio tersebut bahwa usahatani pepaya relatif efisien dan mampu memberikan keuntungan anatar 1,57 hingga 5,50 kali dari biaya produksi (Limbong, 2012; Budiyanti dan Sunyoto, 2011).

Tujuan penelitian ini untuk mengevaluasi jenis pepaya yang beradaptasi baik berdasarkan pertumbuhan, produksi, dan mutu buah di lahan kering Palangka Raya.

\section{METODE PENELITIAN}

Penelitian dimulai pada pada bulan Juli 2018 hingga Juli 2019, terdiri dari penyemaian selama dua bulan dan penanaman di mulai pada bulan September 2018. Penelitian dan pengamatan di lapangan akan berlangsung sepuluh bulan dimana panen tahap pertama diperkirakan selesai. Lokasi penelitian "on Farm Research" di lahan petani terletak pada agroekosistem lahan kering di Kelurahan Banturung, Kecamatan Bukit Batu, Kota Palangka Raya. Penelitian dirancang menggunakan RAK3x4, Rancangan Acak Kelompok tiga perlakuan dan diulang sebanyak empat kali. Setiap perlakuan terdiri dari tiga tanaman pepaya yang ditanam dengan jarak tanam $2 \times 3 \mathrm{~m}$. Jumlah tanaman pepaya secara keseluruhan adalah 36 tanaman.

Perlakuan yang digunakan adalah tiga varietas pepaya, yaitu: Merah Delima produksi Balai Penelitian Tanaman Buah di Solok, Jupe produksi PT Aditya Sentana Agro di Malang, dan California Madu produksi PT Benih Unggul Sejati di Jember.

Sebelum penanaman dilakukan pembuatan lubang tanam dengan ukuran $30 \times 30 \times 30 \mathrm{~cm}$ dan dibiarkan terpapar sinar matahari selama dua minggu. Pupuk dasar diberikan dengan mencampur tanah galian lubang tanam dan dikembalikan ke lubang tanam. Pemupukan dasar menggunakan pukan ayam 10 $\mathrm{kg} / \mathrm{tanaman}$ atau (tnm), Dolomit 0,5 kg/tnm, SP-36 $200 \mathrm{~kg} / \mathrm{tnm}$. Pemupukan susulan menggunakan NPK 16:16:16 pada 1 dan 2 BST (Bulan Setelah Tanam) sebesar 0,100 kg/tnm, umur 2-3 BST 150 gr, umur 4-6 BST $0,200 \mathrm{~kg} / \mathrm{tnm}$ dan pada umur 4 BST ditambah 
pukan ayam $10 \mathrm{~kg} / \mathrm{tnm}$, umur 7 BST 0,300 $\mathrm{kg} / \mathrm{tnm}$.

Penyiraman dilakukan dengan melihat kelembaban tanah, jika kering maka dilakukan penyiraman menggunakan air tanah. Pengendalian OPT (Organisme Pengganggu Tanaman) dilakukan rutin tiap bulan menggunakan pestisida secara terukur.

Parameter yang diamati adalah tinggi tanaman, diameter pangkal batang $10 \mathrm{~cm}$ dari atas tanah, lebar tajuk pada umur 3 dan 6 BST, sedangkan parameter produksi adalah jumlah buah per tanaman, berat buah per biji dan berat buah per tanaman, serta tingkat kemanisan.

Karakteristik iklim dan sifat fisik tanah lokasi penelitian juga dikaji. Data curah hujan 10 tahun diperoleh dari BP3K Tangkiling (2019). Sedangkan analisis tanah dilakukan di Balai Penelitian Tanaman lahan Rawa Banjarbaru. Kesesuaian lahan aktual menggunakan sistem FAO (1976) yang mencocokan antara kriteria kesesuaian lahan tanaman pepaya dengan sifat tanah yang dianalisis. Kelas kesesuaian lahan aktual dilakukan pada tingkat subklas. Guna melihat pengaruh antar perlakuan pada parameter tanaman digunakan uji DMRT taraf 5\%,

\section{HASIL DAN PEMBAHASAN}

\section{Kondisi Hujan di Lokasi Penelitian}

Kondisi curah hujan di lokasi penelitian berdasarkan data rata-rata 10 tahun (20092018) mencapai 2.927 mm/th (Gambar 1). Berdasarkan tipe iklim Schmidt-Ferguson termasuk iklim A, dan berdasarkan Tipe Agroklimat Oldeman tergolong tipe B atau memiliki bulan basah 7-9 bulan berturut-turut.

Pada saat penanaman di bulan September terlihat memasuki akhir musim kemarau, sedangkan pada masa pembungaan yaitu pada umur 3 bulan telah memasuki musim hujan.

Kondisi curah hujan nampaknya sangat penting dalam mempengaruhi tanaman pepaya. Jika tanaman pepaya selama fase pertumbuhan kekurangan air maka mempengaruhi terhadap pertumbuhan dan hasil. Namun sebaliknya apabila pada fase pertumbuhan ketersediaan airnya berlebihan atau curah hujan tinggi juga akan berpengaruh

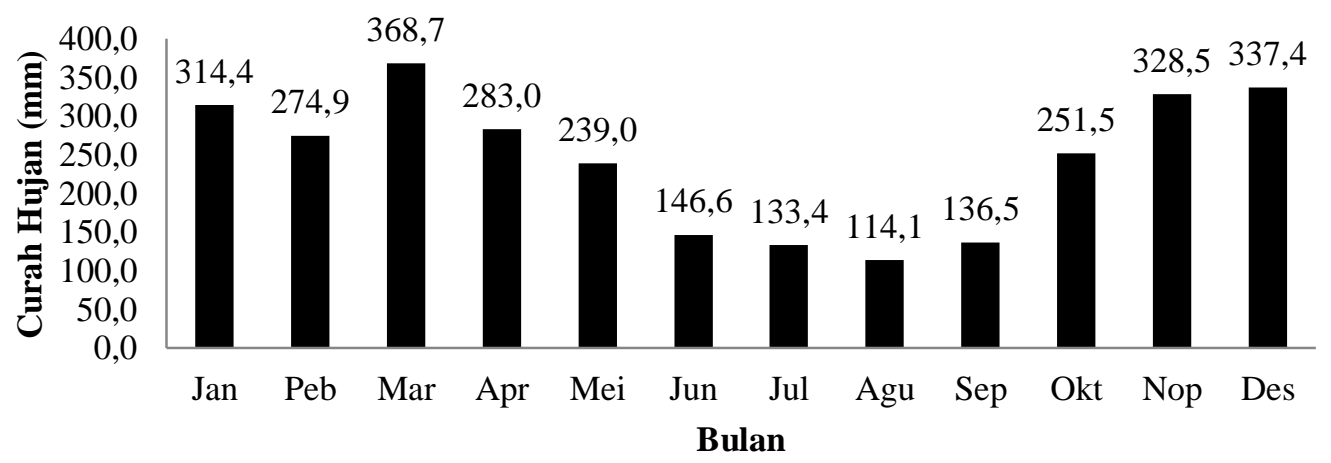

Gambar 1. Kondisi curah hujan rata-rata bulanan selama 10 tahun (2009-2018) di lokasi penelitian. 
buruk juga terhadap pertumbuhan dan hasil akibat tercucinya pupuk yang diberikan, menurunnya aktifitas fotosintesis akibat banyaknya hari tertutup awan, dan meningkatnya serangan penyakit.

Ritung et al (2011) curah hujan yang diharapkan pepaya tumbuh optimal (sangat sesuai dan sesuai) adalah pada kisaran 800$2.000 \mathrm{~mm} / \mathrm{th}$, namun jika curah hujan tahunan melebihi $2.000 \mathrm{~mm} / \mathrm{th}$ maka akan menurunkan kesesuaian pepaya untuk tumbuh dan berproduksi optimal (sesuai marjinal).

Kondisi curah hujan tahunan di lokasi penelitian menunjukkan nilai yang sangat tinggi yaitu $2.927 \mathrm{~mm} / \mathrm{th}$. Hal tersebut jelas akan mempengaruhi pertumbuhan dan produksi tanaman pepaya menjadi kurang optimal.

Selain jumlah curah hujan rata-rata tahunan, maka pola curah hujan merupakan hal penting dalam mempengaruhi produksi pepaya. Pola curah hujan mempengaruhi produktivitas pepaya, pola curah hujan dengan tiga puncak hujan dengan sebaran yang merata akan memberikan kontribusi besar terhadap produktivitas pepaya yang tinggi, dibandingkan curah hujan yang tidak merata sepanjang tahun Olubode (2012). Namun demikian kondisi curah hujan di lokasi penelitian hanya memiliki pola puncak curah hujan tunggal dan menunjukkan ketersediaan air hujan tidak merata sepanjang tahun. Hal ini merupakan salah satu faktor menyebabkan produktivitas tidak optimal. Dengan demikian perlu penambahan atau penyiraman air pada kondisi curah hujan sangat rendah di bulan-bulan kering (Juni, Juli , Agustus, dan September)

\section{Kelas Kesesuaian Lahan Aktual}

Faktor pembatas utama dalam pengembangan pepaya di lahan kering di Kelurahan Banturung, Kota Palangka Raya terdiri dari tiga karaktersitik lahan. Ketiga faktor pembatas tersebut memiliki derajat lebih berat dari faktor pembatas lainnya akan ditulis pada urutan pertama. Berdasarkan faktor pembatas yang ada di lokasi penelitian pepaya terdapat tiga faktor pembatas, yaitu: ketersediaan air (wa) pada karakteristik curah hujan di lokasi mencapai 2.294/th, faktor pembatas ketersediaan oksigen (oa) pada karakteristik drainae tergolong agak cepat, dan faktor pembatas hara tersedia (nr) pada karakteristik lahan $\mathrm{pH}$ tanah memiliki nilai 5,53 (Tabel 1). Berdasarkan ketetapan FAO (1976) maka untuk penetapan kelas kesesuaian lahan aktual pada tingkat subkelas sebaiknya digunakan dua faktor pembatas terberat, maka lokasi penelitian termasuk S3wa,oa (Kelas Sesuai Marjinal). Faktor pembatas hara tersedia tidak digunakan dalam faktor pembatas kelas kesesuaian ini, karena dapat diperbaiki dengan tingkat pengelolaan lebih ringan. 
Tabel 1. Kelas Kesesuaian Lahan Aktual untuk Pengembangan Pepaya di Lahan Kering Dataran Rendah Kelurahan Banturung, Palangka Raya

\begin{tabular}{|c|c|c|c|c|c|c|}
\hline \multirow{2}{*}{$\begin{array}{c}\text { Persyaratan } \\
\text { penggunaan/ } \\
\text { karakteristik lahan }\end{array}$} & \multicolumn{4}{|c|}{ Kelas kesesuaian lahan } & \multirow[t]{2}{*}{ Nilai } & \multirow[t]{2}{*}{$\begin{array}{l}\text { KKL } \\
\text { aktual }\end{array}$} \\
\hline & S1 & S2 & S3 & $\mathrm{N}$ & & \\
\hline \multicolumn{7}{|l|}{ Temperatur (tc) } \\
\hline Temperatur rerata $\left({ }^{\circ} \mathrm{C}\right)$ & $25-28$ & $\begin{array}{l}28-34 \\
20-25\end{array}$ & $\begin{array}{l}34-38 \\
15-20\end{array}$ & $\begin{array}{l}>38 \\
<15\end{array}$ & $25-30$ & S1 \\
\hline \multicolumn{7}{|l|}{ Ketersediaan air (wa) } \\
\hline Curah hujan (mm) & $\begin{array}{r}1.000- \\
1.500\end{array}$ & $\begin{array}{r}800-1.000 \\
1.500- \\
2.000\end{array}$ & $\begin{array}{r}600-800 \\
>2.000\end{array}$ & $<600$ & 2.294 & S3 \\
\hline \multicolumn{7}{|c|}{ Ketersediaan oksigen (oa) } \\
\hline Drainase & baik, sedang & $\begin{array}{l}\text { Agak } \\
\text { terhambat }\end{array}$ & $\begin{array}{l}\text { Terhambat, } \\
\text { Agak cepat }\end{array}$ & $\begin{array}{l}\text { sangat } \\
\text { terham- } \\
\text { bat, cepat }\end{array}$ & agak cepat & S3 \\
\hline \multicolumn{7}{|l|}{ Media perakaran (rc) } \\
\hline Tekstur & $\begin{array}{r}\text { Sedang, } \\
\text { agak halus, } \\
\text { halus }\end{array}$ & Agak kasar & Sangat halus & kasar & $\begin{array}{l}\text { lempung } \\
\text { berpasir }\end{array}$ & S2 \\
\hline Bahan kasar (\%) & $<15$ & $15-35$ & $35-55$ & $>55$ & $<15$ & S1 \\
\hline Kedalaman tanah $(\mathrm{cm})$ & $>75$ & $>75$ & $50-75$ & $<50$ & 200 & S1 \\
\hline \multicolumn{7}{|l|}{ Gambut: } \\
\hline Ketebalan $(\mathrm{cm})$ & $<50$ & $50-100$ & $100-200$ & $>200$ & - & - \\
\hline \multicolumn{4}{|l|}{ Retensi hara (nr) } & & - & - \\
\hline KTK tanah $(\mathrm{cmol})$ & $>16$ & $5-16$ & $<5$ & & 14,02 & S2 \\
\hline Kejenuhan basa (\%) & $>35$ & $20-35$ & $<20$ & & 49,36 & $\mathrm{~S} 1$ \\
\hline $\mathrm{pH} \mathrm{H}_{2} \mathrm{O}$ & $6,0-6,6$ & $\begin{array}{r}5,5-6,0 \\
>6,6\end{array}$ & $<5,5$ & & 5,53 & S3 \\
\hline C-organik (\%) & $>1,2$ & $0,8-1,2$ & $<0,8$ & & 0,97 & S2 \\
\hline \multicolumn{7}{|l|}{ Hara tersedia (nr) } \\
\hline $\mathrm{N}$ total $(\%)$ & Sedang & rendah & Sangat rendah & & sedang & S1 \\
\hline $\mathrm{P}_{2} \mathrm{O}_{5}(\mathrm{mg} / 100 \mathrm{~g})$ & Sedang & Rendah & Sangat rendah & & Sangat tinggi & S1 \\
\hline $\mathrm{K}_{2} \mathrm{O}(\mathrm{mg} / 100 \mathrm{~g})$ & Sedang & rendah & Sangat rendah & & rendah & S2 \\
\hline \multicolumn{7}{|l|}{ Toksisitas (xc) } \\
\hline $\begin{array}{l}\text { Salinitas (dS/m) } \\
\text { Sodisitas (xn) }\end{array}$ & $<2$ & $2-3$ & $3-4$ & $>4$ & - & - \\
\hline $\begin{array}{l}\text { Sodisitas (xn) } \\
\text { Alkalinitas/ESP (\%) }\end{array}$ & $<15$ & $15-20$ & $20-25$ & $>25$ & - & - \\
\hline $\begin{array}{l}\text { Bahaya sulfidik (xs) } \\
\text { Kedalaman sulfidik } \\
(\mathrm{cm})\end{array}$ & $>125$ & $100-125$ & $60-100$ & $<60$ & - & - \\
\hline \multicolumn{7}{|l|}{ Bahaya erosi (eh) } \\
\hline Lereng $(\%)$ & $<8$ & $8-15$ & $15-30$ & $>30$ & 3 & S1 \\
\hline Bahaya erosi & $\begin{array}{l}\text { sangat } \\
\text { ringan }\end{array}$ & $\begin{array}{l}\text { Sedang- } \\
\text { ringan }\end{array}$ & berat & $\begin{array}{r}\text { sangat } \\
\text { berat }\end{array}$ & ringan & S2 \\
\hline \multicolumn{7}{|c|}{ Bahaya banjir /gengangn pada masa tanam (fh) } \\
\hline Tinggi $(\mathrm{cm})$ & - & - & 25 & $>25$ & 0 & S1 \\
\hline Lama (hari) & - & - & $<7$ & $\geq 7$ & 0 & S1 \\
\hline \multicolumn{7}{|l|}{ Penyiapan lahan (lp) } \\
\hline $\begin{array}{l}\text { Batuan di permukaan } \\
(\%)\end{array}$ & $<5$ & $5-15$ & $15-40$ & $>40$ & $<5$ & S1 \\
\hline Singkapan batuan $(\%)$ & $<5$ & $5-15$ & $15-25$ & $\begin{array}{r}>25 \\
\text { las kesesuaia }\end{array}$ & $\begin{array}{r}<5 \\
\text { n lahan aktual }\end{array}$ & $\begin{array}{l}\text { S1 } \\
\text { S3wa,oa }\end{array}$ \\
\hline
\end{tabular}

Keterangan: KKL=Kelas Kesesuaian Lahan. Sumber: Ritung et al (2011). 
Tingkatan $\mathrm{pH} \quad 5,5$ atau kurang akan menghambat produksi pepaya, karena kondisi tersebut menyebabkan terjadinya defisiensi unsur hara antara lain Nitrogen, Fosfor, Kalium, Kalsium, Besi, Zink, Tembaga, dan Boron (Medina et al, 2003). Perbaikan tanah yang masam adalah dengan pemberian kapur, sehingga unsur hara akan lebih tersedia bagi tanaman,

\section{Parameter Pertumbuhan}

Tiga parameter pertumbuhan yang diukur pada umur 3 dan 6 BST, hanya pada tinggi tanaman ada perbedaan nyata. Tinggi tanaman pepaya varietas Madu adalah paling rendah dan berbeda nyata dengan pepaya Merah Delima $(210,4 \mathrm{~cm})$ tertinggi disusul Jupe (192,5 cm) (Tabel 2).

Parameter diameter pangkal batang merupakan parameter penting, sebab memiliki fungsi ketahanan tanaman terhadap daya sangganya, Nampak bahwa Merah Delima memiliki diameter pangkal batang yang paling besar $(8,8 \mathrm{~cm})$ pada umur $6 \mathrm{BST}$, dibandingkan varietas lainnya. Hal ini dpat menjadi petunjuk bahwa pepaya Merah
Delima lebih tahan rebah pada tanah-tanah yang memiliki kapasitas peyangga rendah, seperti di lahan rawa bergambut maupun gambut (Martias et al.,2011; Firmansyah, 2014) mengembangkan pepaya Merah Delima di lahan rawa pasang surut, pada tanah sulfat masam potensial bergambut.

\section{Parameter Produksi}

Parameter produksi yang diukur ada tiga komponen yaitu jumlah buah, bobot buah per butir dan bobot buah per pohon. Berdasarkan ketiga parameter tersebut nampaknya Jupe tertinggi dan berbeda nyata dengan varietas lainnya (Tabel 3). Tingginya produksi Jupe dikaitkan dengan parameter pertumbuhan kemungkinan disebabkan lebar tajuk yang lebih tinggi dibandingkan varietas lainnya. Menurut Babu et al.,(1989) dalam Olubode et al (2016) ada hubungan postif anatara parameter pertumbuhan dan parameter produksi, salah satu diantaranya adalah luas daun.

Khusus untuk pepaya Merah Delima, maka produksi di lokasi penelitian belum menunjukkan potensi optimal. (Budiyanti

Tabel 2. Parameter Pertumbuhan Pepaya pada Umur 3 dan 6 BST

\begin{tabular}{lcccccc}
\hline \multirow{1}{*}{ Varietas } & \multicolumn{3}{c}{3 BST } & & \multicolumn{3}{c}{ 6 BST } \\
\cline { 2 - 7 } & $\begin{array}{c}\text { Tinggi } \\
\text { Tanaman } \\
(\mathrm{cm})\end{array}$ & $\begin{array}{c}\text { Diameter } \\
\text { Batang } \\
(\mathrm{cm})\end{array}$ & $\begin{array}{c}\text { Lebar } \\
\text { Tajuk } \\
(\mathrm{cm})\end{array}$ & $\begin{array}{c}\text { Tinggi } \\
\text { Tanaman } \\
(\mathrm{cm})\end{array}$ & $\begin{array}{c}\text { Diameter } \\
\text { Batang } \\
(\mathrm{cm})\end{array}$ & $\begin{array}{c}\text { Lebar } \\
\text { Tajuk } \\
(\mathrm{cm})\end{array}$ \\
\hline Merah & $64 \mathrm{~b}, 7 \mathrm{~b}$ & 3,43 & $117,3 \mathrm{a}$ & $210,4 \mathrm{~b}$ & 10,1 & 193,3 \\
Delima & $64,6 \mathrm{~b}$ & 4,24 & $146,6 \mathrm{~b}$ & $192,5 \mathrm{~b}$ & 8,8 & 214,2 \\
Jupe & $52,2 \mathrm{a}$ & 3,44 & $106,1 \mathrm{a}$ & $173,3 \mathrm{a}$ & 8,6 & 191,7 \\
Madu & & & & & & \\
\hline
\end{tabular}

Keterangan: Huruf yang sama pada kolom yang sama tidak berbeda nyata pada uji DMRT taraf 5\%. 
Firmansyah dan Pribadi, ADAPTASI TIGA VARIETAS PEPAYA...

Tabel 3. Parameter Produksi Pepaya umur 8 BST

\begin{tabular}{lrrr}
\hline \multicolumn{1}{c}{ Varietas } & $\begin{array}{c}\text { Jumlah Buah } \\
\text { umur 6 BST }\end{array}$ & $\begin{array}{r}\text { Bobot Buah per Butir } \\
(\mathrm{kg} / \mathrm{butir})\end{array}$ & $\begin{array}{c}\text { Bobot Buah Per Pohon } \\
(\mathrm{kg} / \text { pohon })\end{array}$ \\
\hline Merah Delima & $21,3 \mathrm{ab}$ & $0,988 \mathrm{a}$ & $21,3 \mathrm{a}$ \\
Jupe & $28,0 \mathrm{~b}$ & $1,223 \mathrm{~b}$ & $34,1 \mathrm{~b}$ \\
Madu & $19,0 \mathrm{a}$ & $1,098 \mathrm{ab}$ & $20,7 \mathrm{a}$ \\
\hline
\end{tabular}

Keterangan: Huruf yang sama pada kolom yang sama tidak berbeda nyata pada uii DMRT taraf 5\%.

dan Noflindawati, 2012) menujukkan pepaya

merah delima mampu berproduksi 70-90

t/ha/musim, namun di penelitian ini hanya mampu $25 \mathrm{t} / \mathrm{ha} /$ musim dengan asumsi jumlah tanaman 1.200 pohon/ha. Sunyoto et al. (2015) Merah Delima mampu menghasilkan 35 buah per pohon dengan bobot buah 0,83 $\mathrm{kg} /$ butir. Hal ini menunjukkan bahwa jumlah buah berkorelasi negatif dengan bobot buah. Hal tersebut sejalan dengan penelitian yang dilakukan, bahwa hasil menunjukkan bobot buah lebih tinggi namun jumlah buah lebih rendah.

Jika ditinjau dari ukuran, nampak bahwa ukuran semua varietas pepaya yang diteliti pada kategori sedang, antara 0,988 - 1,223 kg/butir. (Budiyanti, 2016) buah pepaya berukuran kecil memiliki berat 0,3-0,8 $\mathrm{kg} /$ butir, buah pepaya berukuran sedang memiliki berat $0,8-1,9 \mathrm{~kg} /$ butir, sedangkan buah pepaya berukuran besar memiliki berat lebih dari $2 \mathrm{~kg} /$ butir Berbagai jenis buah pepaya ada dipasaran, namun konsumen saat ini menyukai buah pepaya berukuran kecil hingga sedang dibandingkan pepaya berukuran besar.

Selain itu nampaknya pepaya varietas Jupe secara genetik lebih toleran terhadap lingkungan penelitian yang memiliki faktor penghambat berat seperti ketersediaan air yang tidak merata serta ketersediaan oksigen yang menunjukkan drainase agak cepat. Ceccoli et al. (2013) bahwa pepeya hibrida lebih tinggi dibandingkan pepaya lokal di lingkungan yang terkontrol yaitu green house dibandingkan di lapangan. Jumlah dan bobot buah menentukan produksi tanaman.

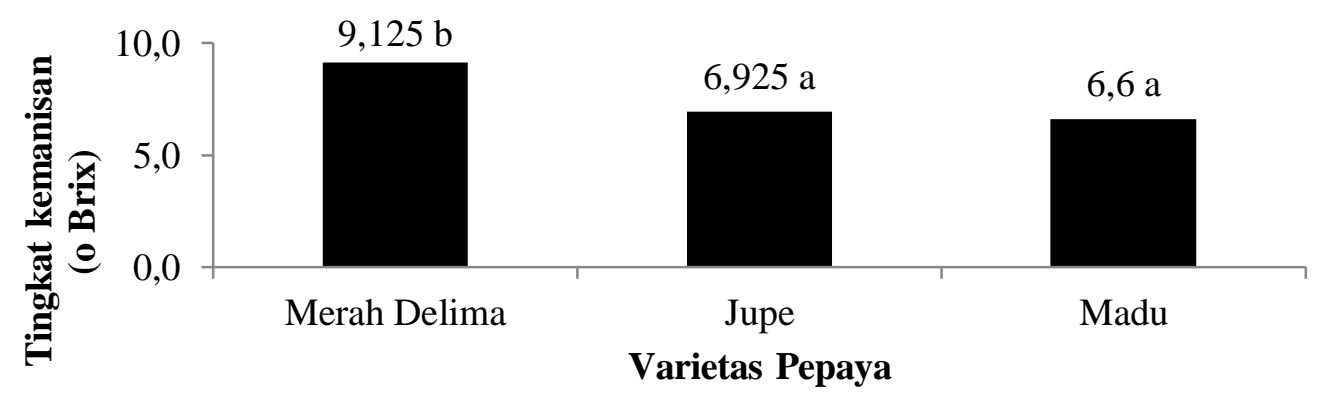

Gambar 2. Kualitas buah pepaya berdasarkan tingkat kemanisannya. 

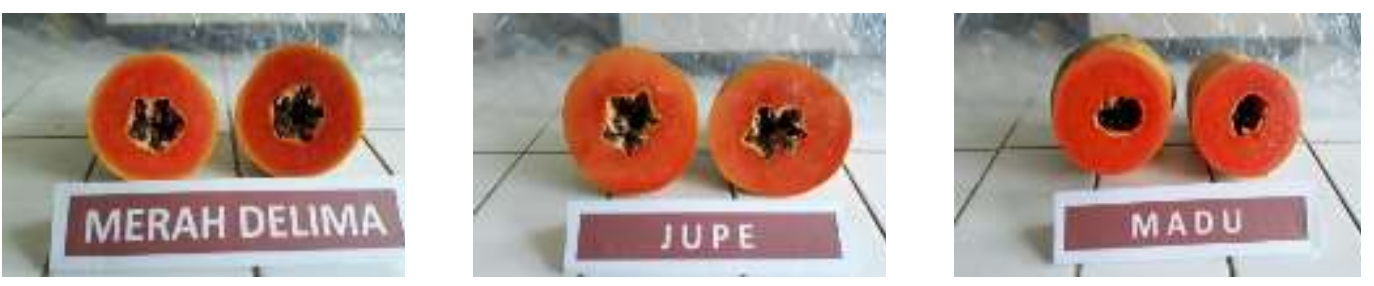

Gambar 3. Penampilan buah pepaya Merah Delima, Jupe dan Madu.

\section{Parameter Mutu}

Berdasarkan tingkat kemanisannya, maka pepaya Merah Delima adalah paling tinggi dan berbeda nyata dibandingkan pepaya Jupe ataupun pepaya Madu (Gambar 2-3). Rasa manis merupakan faktor utama yang menentukan kepuasan konsumen kepada buah papaya (Prihatiningtyas et al. 2015). Beberapa genotip papaya memiliki tingkat kemanisan 10-11 ${ }^{\circ}$ Brix (Fatria dan Noflindawati, 2014). Namun demikian untuk tingkat kemanisan pepaya Merah Delima masih belum optimal, sebab kemanisan pepaya Merah Delima pada beberapa lokasi di Indonesia mencapai $13-15{ }^{\circ}$ Brix (Martias et al., 2011).

\section{KESIMPULAN}

Lokasi penelitian memiliki tingkat kesesuaian lakan aktual untuk pengembangan pepaya adalah S3aw,oa atau tingkat Sesuai Marjinal dengan faktor penghambat terberat ketersediaan air (wa) dan ketersedian oksigen (oa). Pepaya varietas Jupe memiliki keunggulan dalam parameter produksi yaitu jumlah buah per tanaman, berat buah per butir dan berat buah per tanaman dibandingkan Merah Delima dan Madu. Pepaya varietas
Merah Delima menghasilkan tingkat kemanisan buah paling tinggi dibandingkan Jupe dan Madu.

\section{UCAPAN TERIMAKASIH}

Keberhasilan penelitian varietas pepaya di lahan kering Kota Palangka Raya tak terlepas dari dukungan Kepala BPTP Kalimantan Tengah, Dr. Ir. F.F. Munir, M.Sc. Ucapan terimakasih juga ditujukan kepada petani kooperator Suroto Sasatri Wahyudi yang mampu melaksanakan kegiatan dengan baik.

\section{DAFTAR PUSTAKA}

Ali, A., S. Devarajan, M.I. Waly, M.M. Essa. And M.S. Rahman. 2011. Nutritional and medical values papaya (Carica papaya L.). Nova Science Publisher, Inc. P:1-18.

Budiyanti, T. 2016. Efek heterosis dan aksi gen ukuran buah pada hibrida pepaya. Jur. Agroekotek. 8(1):38-46.

dan Sunyoto. 2011. Varietas unggul baru pepaya merah delima si merah yang manis. Sinar Tani. Edisi 28 Nopember. No. 3429 Tahun XLII. Hal 5-7.

dan Noflindawati. 21012. Pepaya Merah Delima dalam meningkatkan pendapatan dan kesejahteraan masyarakat. Inovasi Hortikultura Pengungkit Peningkatan Pendapatan Rakyat. Hal: 141-147. 
BP3K Tangkiling. 2018. Laporan curah hujan Kecamatan Bukit Batu. Kota Palangka Raya. 15 hal.

Ceccoli, G., E.S. Panigo, N. Garglio, J.C. Favro, and C.A. Bouzo. 2013. Fruit yield nd growth prameters of several Carica papaya L. Genotypes in a temperate climate. Rev. FCA UNCUYO. 45(2):299-310.

FAO. 1976. A framework for land evaluation. Soil Resources Management and Conservation Service. Land and Water Development Division. FAO Soil Bulletin No.Development Division. FAO Soil Bulletin No.2. FAO-UNO, Rome.

Fatria, D., dan Noflindawati. 2014. Karakteristik kualitas buah empat genotip papaya (Carica papaya L.) koleksi Balai Penelitian Tanaman Buah Tropika. J. Floratek. 9:1-5.

Firmansyah, M.A. 2014. Manisnya Budidaya Pepaya di lahan gambut. Tabloid Sinar Tani. 27 Janurai 2014.

Indriyati, N.L.P., Affandi, dan D. Sunarwati. 2008. Pengelolaan kebun pepaya sehat. Balai Penelitian Tanaman Buah Tropika. Pusat Penelitian dan Pengembangan Hortikultura. Badan Penelitian dan Pengembangan Pertanian. Kementerian Pertanian. 33 hal.

Limbong, J. 2012. Analisis kelayakan finansial usahatani pepaya (Carica papaya L.) di Muang Dalam Kelurahan Lempake Kecamatan Samarinda Utara. EPP. 9(2):1-7.

Martias, F. Nasution, Noflindawati, T. Budiyanti, dan Y. Hilman. 2011. Respon pertumbuhan dan produksi pepaya terhadap pemupukan Nitrogen dan Kalium di Lahan Rawa Pasang Surut. J. Hort. 21(4):324-330.

Medina, J.D.L.C., G.V. Guiterrez, and H.S. Garcia. 2003. Pawpaw: post-harvest operation. Food andriculture Organization of The United Nations. $70 \mathrm{p}$.
Olubode, O.O. 2012. Influence of seasonal variations on component of pawpaw / okra mixtures in a pawpaw based cropping system. Biological Agriculture \& Horticulture. 28:1-15.

Olubode, O.O., O.M. Odeyemi, and I.O.O.Aiyelaagbe. 2016. Influence of environmental factor and production practice on the growth and productivity of pawpaw (Carica papaya L.) in South Western Nigeria-A Review. Fruits. 71(6):341-361.

Pesqueirq, M.C., and J.N. farfan. 2017. Domestication and genetics of papaya: a review. Frontier in Ecology and Evolution. 5:1-9. www. frontiersin.org.

Prihatiningtyas, R., A. Setiawan, N.H. Wijaya. 2015. Analisis kualitas pada rantai pasok buah papaya Calina. Jurnal Manajemen dan Organisasi. 6(3):206224.

Ritung, S., K. Nugroho, A. Mulyani, dan E. Suryanti. 2011. Petunjuk teknis evaluasi lahan untuk komoditas pertanian. Balai Besar Penelitian dan Pengembangan Sumberdaya Lahan Pertanian. Badan Penelitian dan Pengembangan Pertanian. Kementerian Pertanian. 161 hal.

Silva, J.R., W.P. Rodrigues., K.F. Ruas, J.S.Paixiao, R.S. Nunes de Lima, J.A.M. Filho, J.A.C. Garcia, B. Scaffer, J.C. Gonzales, and E. Compostrini. 2019. Light, photosynthetic capacity and growth of papaya (Carica papaya L.): a short review. AJCS. 13(3):480485).

Sunyoto, T. Budiyanti, Noflindawati, D. Fatria. 2013. Uji stabilitas lima genotipe pepaya di tiga lokasi. J. Hort. 23(2):129-136.

, L. Octriana, D. Fatria, Hendri, dan Kusnadi. 2015. Evaluasi pertumbuhan dan hasil beberapa pepaya hibrida di wilyah pengembangan Bogor. J. Hort. 25(3):193-200. 